\title{
Freeze-fracture and Freeze-etching Study of Encystment of Phytophthora palmivora Zoospores
}

\author{
By MARIA LUIZA B. NOGUEIRA,* PEDRO PINTO DA SILVA $\dagger$ \\ AND SALOMON BARTNICKI-GARCIA* \\ * Department of Plant Pathology, University of California, Riverside, \\ California $9252 \mathrm{I}$, U.S.A. \\ $\dagger$ Laboratory of Pathophysiology, National Cancer Institute, Bethesda, \\ Maryland 200I4, U.S.A.
}

(Received 23 May 1977)

\begin{abstract}
Zoospores of Phytophthora palmivora were induced to encyst synchronously and changes in morphology, particularly in surface structure, were examined by freeze-fracture and freezeetching techniques.

A uniform 'fuzzy coat', 20 to $25 \mathrm{~nm}$ thick, covers the plasma membrane. This hitherto unknown structure surrounds the entire zoospore body and flagella. No structural correspondence between cyst wall microfibrils and plasma membrane particles was found. The pattern of distribution of plasma membrane particles remains unchanged during encystment.
\end{abstract}

\section{INTRODUCTION}

Encystment of fungal zoospores is an attractive process for the study of cell wall neogenesis. The zoospores are natural protoplasts easily obtained, in large and uniform populations, without the use of lytic enzymes, osmoticums or other agents. In a population of zoospores of Phytophthora palmivora, agitation initiates cell wall genesis synchronously (Tokunaga \& Bartnicki-Garcia, I97I $a$ ) and, in about $2 \mathrm{~min}$, the cells develop a thin but uniform cyst wall made of tightly knit microfibrils (Tokunaga \& Bartnicki-Garcia, 197I b). In carbonplatinum replicas, the surface texture of $P$. palmivora zoospores appears granular, whereas a dense meshwork of randomly oriented microfibrils, with patches of amorphous material, covers the mature cyst (Desjardins, Wang \& Bartnicki-Garcia, 1973). Thin sections of encysting zoospores of Phytophthora or Pythium demonstrate the presence of numerous large vesicles ('peripheral vesicles'; Grove, I97I) close to the inner surface of the plasma membrane (Reichle, I969; Grove, I97I; Hemmes \& Hohl, 197I; Sing \& Bartnicki-Garcia, 1975). Immediately before a microfibrillar cyst wall is formed, peripheral vesicles fuse with the plasma membrane and release glycoproteinaceous material on to the cell surface. This material forms an amorphous, adhesive coat (Sing \& Bartnicki-Garcia, I975). Whether the peripheral vesicles also contain substrate and/or enzymes needed in the elaboration of the cyst wall is unknown. In the present communication, we have employed the techniques of freeze-fracture and freeze-etching to gain further knowledge of the changes in surface structure that occur during the encystment of zoospores of $P$. palmivora. Details of the fusion of peripheral vesicles with the plasma membrane are presented elsewhere (Pinto da Silva \& Nogueira, 1977). 


\section{METHODS}

Cultivation. Phytophthora palmivora strain PII3 was grown at $25^{\circ} \mathrm{C}$ on V-8 juice agar plates for 3 to 4 days in the dark followed by 3 to 4 days of illumination under fluorescent lights (Aragaki \& Hine, I963; Tokunaga \& Bartnicki-Garcia, I97I $a$ ).

Preparation of zoospores. Sporulated cultures were chilled at $\mathrm{I}{ }^{\circ} \mathrm{C}$ for $\mathrm{I} 0 \mathrm{~min}$, and the plates were flooded with $15 \mathrm{ml}$ distilled water at room temperature. Numerous zoospores were liberated, and the suspension was filtered through Whatman no. 4I filter paper to remove fragments of mycelium or sporangia.

Encystment. Encystment was induced by vigorous agitation of the zoospore suspension with a Vortex mixer (Tokunaga \& Bartnicki-Garcia, I97I $a$ ). Samples were agitated for 0, 45, 75 and I80 s. Encystment was stopped by adding glutaraldehyde (in $0 \cdot \mathrm{I}$ M-potassium phosphate buffer, $\mathrm{pH} 7 \cdot 2$ ) to the zoospore suspension, to a final concentration of $\mathrm{I} \%(\mathrm{w} / \mathrm{v})$. The samples were fixed at room temperature for $30 \mathrm{~min}$, and then washed with buffer, resuspended in buffer and stored in the refrigerator.

Freeze-fracture. Fixed zoospores were resuspended in about $\mathrm{I} \mathrm{ml}$ buffer. Fourteen $\mathrm{ml}$ of $25 \%(\mathrm{v} / \mathrm{v})$ glycerol solution in phosphate buffer was added dropwise at room temperature over a period of 10 min to the resuspended zoospores. The suspension was centrifuged at $1000 \mathrm{~g}$ for $10 \mathrm{~min}$, the supernatant was removed, and fresh $25 \%$ glycerol solution was added. The material was then incubated for $30 \mathrm{~min}$ at $37^{\circ} \mathrm{C}$ and for $\mathrm{I} \mathrm{h}$ at room temperature. The material was frozen in the liquid phase of partially solidifed Freon 22 , freezefractured at $-\mathrm{IIO}^{\circ} \mathrm{C}$ in a Balzers $5 \mathrm{IO}$ unit, and immediately shadowed with platinum-carbon with an electron gun. The micrographs are shown with the metal shadowing direction from bottom to top; since no second negatives were employed, shadows appear white.

Freeze-etching. The fixed cells were resuspended and washed twice in distilled water. They were then frozen in distilled water, fractured at $-100{ }^{\circ} \mathrm{C}$, etched (i.e. sublimed) for $\mathrm{I} \mathrm{min}$, shadowed, and observed as described above. For interpretation of fracture faces and etched surfaces, see Pinto da Silva \& Branton (I 970).

\section{RESULTS}

\section{Freeze-fracture studies}

Zoospores or incipient cysts ( 45 to $75 \mathrm{~s}$ agitation) have numerous large 'peripheral' vesicles close to the plasma membrane (Fig. I). In cross-fracture, these peripheral vesicles do not reveal any fibrous substructure. Other more internal cytoplasmic vesicles contain either lamellar bodies with a 'fingerprint' appearance (Fig. I inset) or non-lamellar, probably lipid, bodies (Fig. I). The vesicles with lamellar structures correspond to the fingerprint vesicles seen in thin sections of this fungus and other related organisms (Bartnicki-Garcia \& Hemmes, 1976). Peripheral vesicles are common in zoospores but disappear in the older cysts ( $120 \mathrm{~s}$ agitation or longer). The other vesicles remain in similar numbers during encystment. The pattern of distribution of membrane particles on the plasma membrane appears random (Fig. 2). Freeze-fracture profiles of zoospores reveal the presence of a 'fuzzy coat' of uniform thickness (approximately 20 to $25 \mathrm{~nm}$ ) (Fig. 2) covering the outer surface of the plasma membrane. This fuzzy coat can also be observed on the outer surface of the flagella (Fig. 3). In incipient cysts ( 45 to $75 \mathrm{~s}$ agitation), fracture profiles along the plasma membrane show large concavities that probably correspond to the places where the peripheral vesicles have released their contents (Fig. 4). In older cysts (I $80 \mathrm{~s}$ agitation) the plasma membrane is highly corrugated and is surrounded by the newly formed cyst wall (Fig. 5).

In zoospores at different stages of encystment $(0,45,75$ or $180 \mathrm{~s}$ agitation), the fracture faces of the plasma membrane reveal no special pattern of distribution of membrane particles which might be correlated with the process of cyst wall formation (Figs 2, 4 and 5).

\section{Freeze-etching studies}

The outer surface of unencysted zoospores appears uniformly granular (Fig. 6). The freeze-etch morphology of this outer surface is distinct and related to the freeze-fracture morphology of the plasma membrane (Fig. 6). Clearly, the outer granular surface cor- 

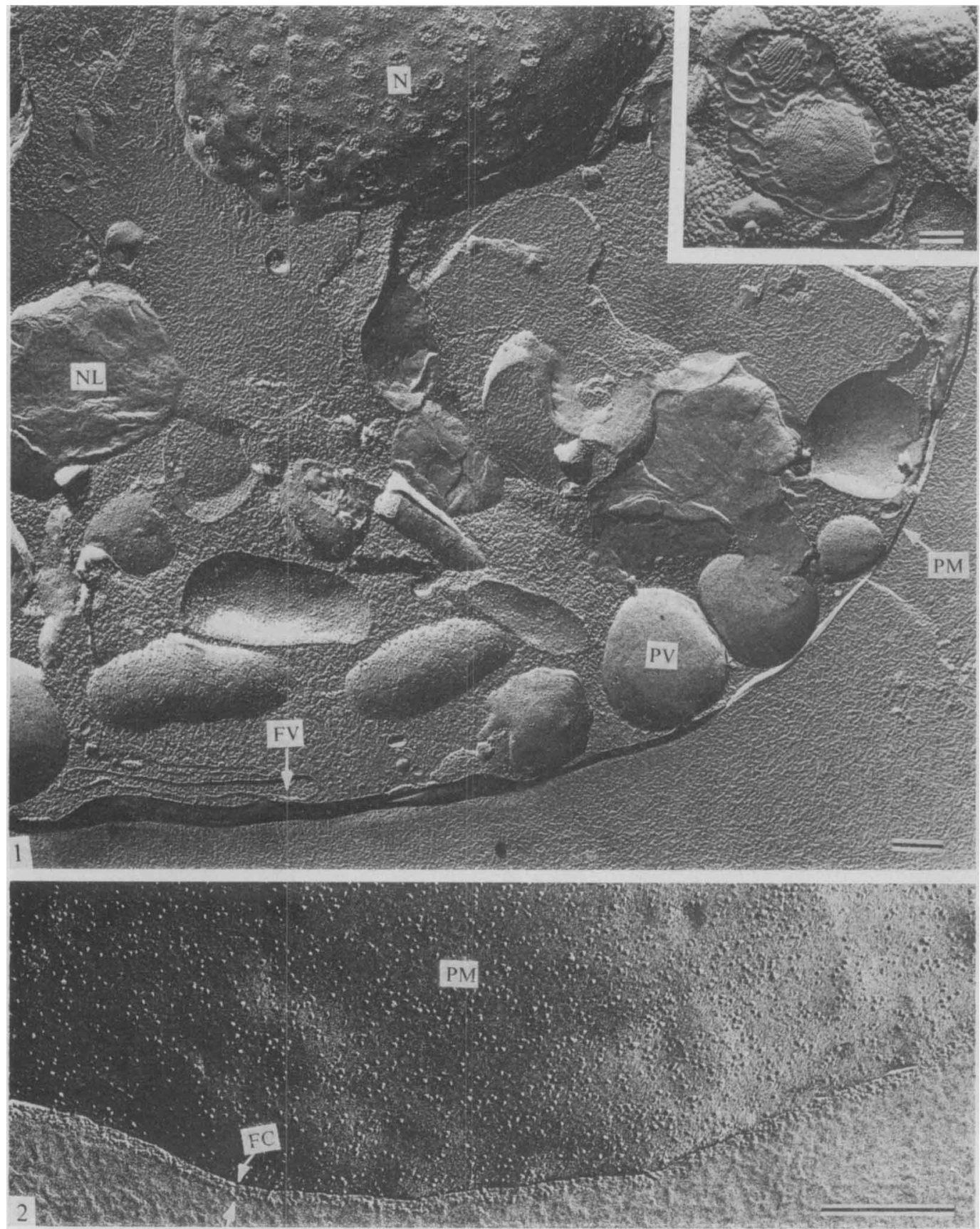

Figs $I$ and 2. Freeze-fracture of unencysted zoospores of $P$. palmivora. Fig. I, internal organization with peripheral vesicles (PV) and flat vesicles (FV) lying in close proximity to the plasma membrane $(\mathrm{PM})$, non-lamellar, probably lipid bodies (NL) and nucleus $(\mathrm{N})$. Inset shows a 'fingerprint' vesicle with characteristic lamellar structure. Fig. 2, fracture face of the plasma membrane with randomly distributed particles. A 'fuzzy coat' (FC) covers the outer surface of the plasma membrane. Bar markers represent $0 \cdot 25 \mu \mathrm{m}$. 

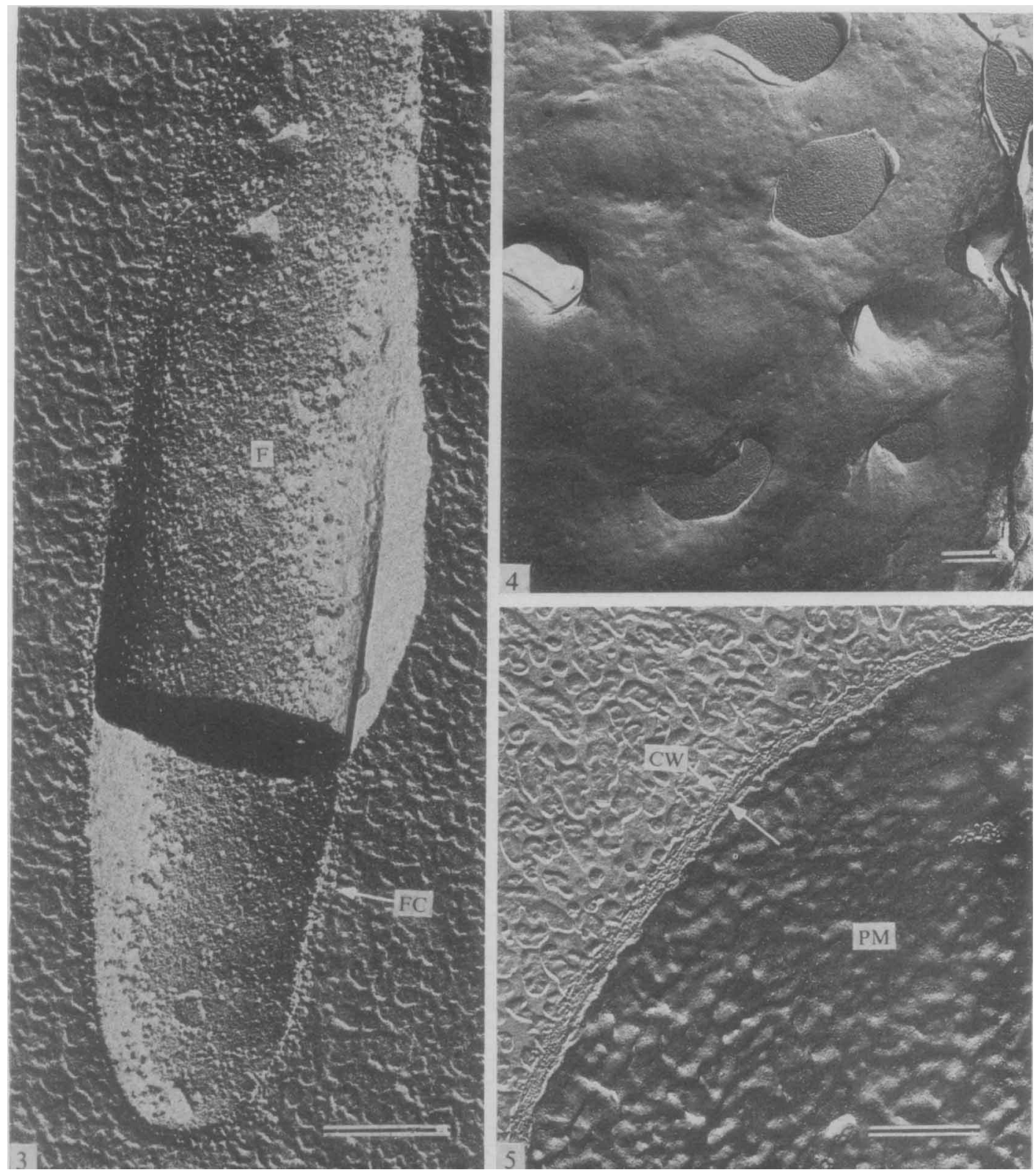

Fig. 3. Freeze-fracture of a flagellum (F) with a 'fuzzy coat' (FC) on the outer surface. Bar marker represents $0.25 \mu \mathrm{m}$.

Figs 4 and 5 . Freeze-fracture of cysts of $P$. palmivora. Fig. 4 , incipient cyst ( $75 \mathrm{~s}$ agitation) with concavities on the plasma membrane suggesting the discharge of vesicular contents. Fig. 5, a mature cyst ( $180 \mathrm{~s}$ agitation) showing a highly corrugated plasma membrane (PM) surrounded by the cell wall (CW). Bar markers represent $0.5 \mu \mathrm{m}$.

responds to the fuzzy coat seen on freeze-fractured zoospores. The samples of young cysts ( 45 or $75 \mathrm{~s}$ agitation) contained cells in various stages of surface development: (i) cells with a granular surface indistinguishable from the fuzzy coat of unencysted zoospores this texture was rare in preparations agitated for $75 \mathrm{~s}$; (ii) cell surfaces with very fine microfibrils (Fig. 7); (iii) cell surfaces covered by distinct microfibrils (frequent in preparations 

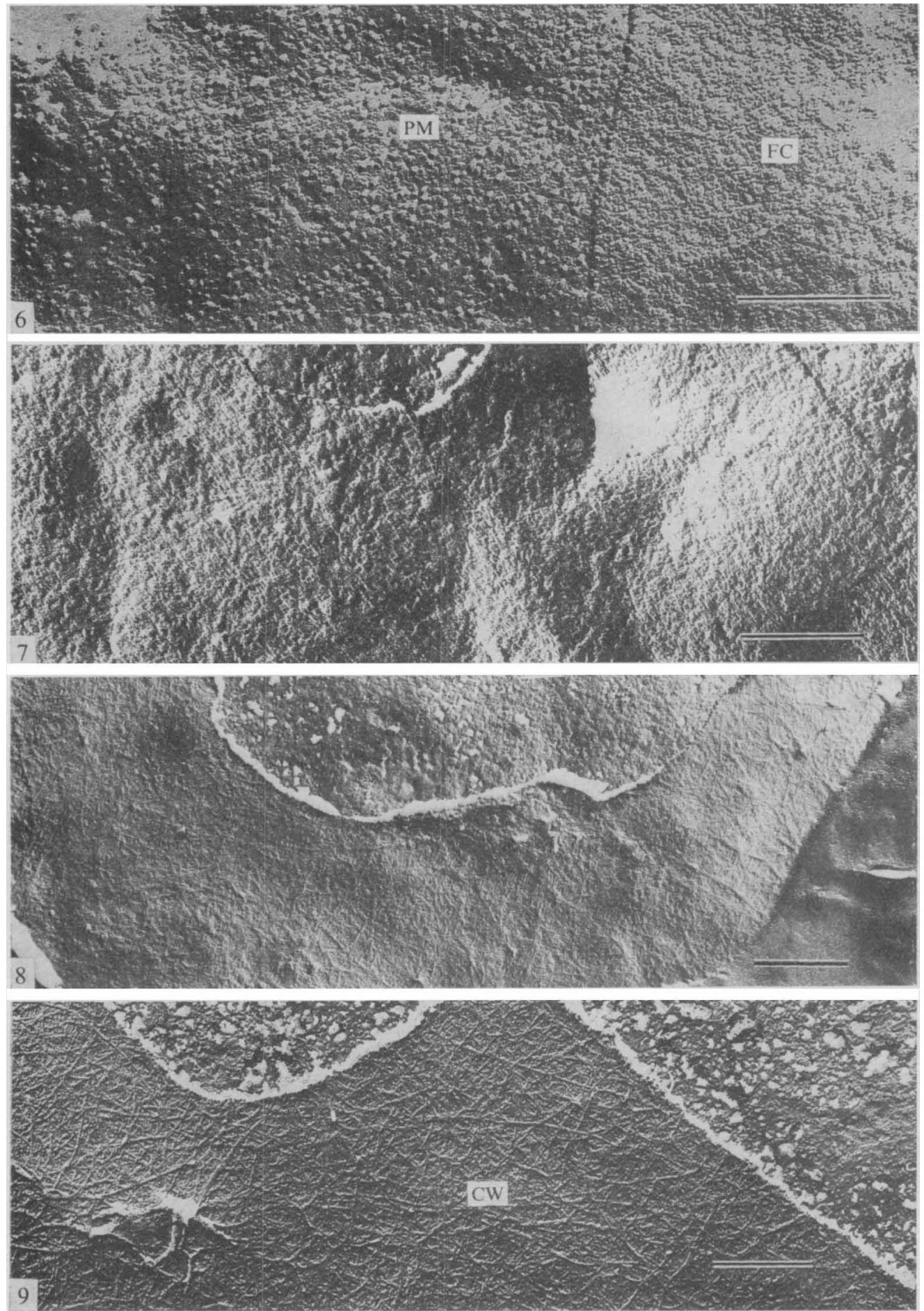

Figs. 6 to 9. Freeze-etch views of progressive stages in cyst wall formation. Fig. 6, unencysted zoospores showing outermost surface or 'fuzzy coat' $(F C)$ and the fracture face of the plasma membrane (PM). Fig. 7, surface of an incipient cyst ( $75 \mathrm{~s}$ agitation) showing fine microfibrils. Fig. 8, intermediate stage of cell wall formation in a cyst agitated for $75 \mathrm{~s}$. Fig. 9, cyst wall (CW) in a mature cyst ( $180 \mathrm{~s}$ agitation) showing randomly oriented microfibrils. Bar markers represent $0.25 \mu \mathrm{m}$ in Figs 6, 7 and 9, and $0.5 \mu \mathrm{m}$ in Fig. 8. 
agitated for $75 \mathrm{~s}$; Fig. 8); (iv) microfibrillar cell surfaces indistinguishable from those of older cysts - these were rarely seen. In samples of older cysts (I $80 \mathrm{~s}$ agitation), the outer surface invariably showed a distinct coat of randomly oriented microfibrils (Fig. 9). There were no obvious connexions between microfibrils and particles on the fracture face of the plasma membrane.

\section{DISCUSSION}

The fuzzy coat covering the plasma membrane of Phytophthora palmivora zoospores has not previously been seen in other fungal zoospores. Whether this coat is unique to this species or genus or is common among fungal zoospores has not been established. Comparable coats have been found in other flagellated eukaryotes. Pathogenic trypanosomes in their bloodstream phase have a I 2 to I $5 \mathrm{~nm}$ thick coat enveloping the entire body including the flagellum (Vickerman, 1969). Due to the limitations of the freeze-fracture technique when applied to structures without intrinsic cleavage planes, it was impossible to see the ultrastructural detail of this coat. The presence of this coat questions the belief (Bartnicki-Garcia, I973) that the plasma membrane is the outermost boundary of the swimming zoospore of Phytophthora palmivora and poses questions of its occurrence in other zoospores and of its physiological role. It is, however, possible that the fuzzy coat may not be an independent structure, but an extension of the zoospore plasma membrane. Although the position of the fuzzy coat suggests an involvement in cyst wall formation, the presence of the coat on the flagellar membrane disputes such involvement.

Our results cannot rule out the possibility that integral membrane components may participate in the formation of cell wall microfibrils, but we did not find obvious structural correspondence between particles of the plasma membrane and cell wall microfibrils. Absence of morphological correspondence between fracture faces and etched surfaces was also noted by Willison \& Cocking (1975) during cell wall regeneration by isolated tobacco mesophyll protoplasts. In their study, linear arrays of particles were occasionally observed on the fracture faces of the plasma membrane but, because the particles were also present in vacuolar membranes, no association could be made with the process of cell wall synthesis. Moor \& Muhlethaler (I963) and Streiblová (I968) observed attachment of short fibrils to some membrane particles on the plasma membrane of yeast cells. Robinson \& Preston (1972) found well ordered arrays of membrane particles with the same orientation as cellulose fibrils on the cell wall of Oocystis apiculata, and proposed that the particles were inyolved in the wall synthesis process. These authors interpreted the particles as structures at the outer surface because they believed that the fracture process followed the membrane surface. However, during freeze-fracture, membranes split along the hydrophobic juncture of the bilayer and the observed particles represent integral structures intercalated and/or, possibly, sequestered into the apolar matrix of the membrane (Pinto da Silva \& Branton, 1970; Pinto da Silva, Moss \& Fudenberg, 1973). It is thus possible that integral membrane proteins intercalated across the bilayer (i.e. with expression at the outer surface) may be involved in the process of synthesis of cell wall components (Brown \& Montezinos, 1976). However, unequivocal evidence does not exist, at present, to establish the involvement of membrane particles (or of integral membrane components) in the synthesis of cell wall microfibrils of fungi. 


\section{REFERENCES}

Aragaki, M. \& Hine, R. B. (1963). Effect of radiation on sporangial production of Phytophthora parasitica on artificial media and detached papaya fruit. Phytopathology 53, 854-856.

BARTNICKI-GARCIA, S. (I973). Cell wall genesis in a natural protoplast: the zoospore of Phytophthora palmivora. In Yeast, Mould and Plant Protoplasts, pp. 77-9I. Edited by J. R. Villanueva, I. Garcia-Acha, S. Gascon and F. Uruburu. London: Academic Press.

Bartnicki-Garcia, S. \& Hemmes, D. E. (I976). Some aspects of the form and function of Oomycete spores. In The Fungal Spore: Form and Function, pp. 593-64I. Edited by D. J. Weber and W. M. Hess. New York: Wiley.

Brown, R. M., Jr \& Montezinos, D. (1976). Cellulose microfibrils: visualization of biosynthetic and orienting complexes in association with the plasma membrane. Proceedings of the National Academy of Sciences of the United States of America 73, 143-147.

Desjardins, P. R., Wang, M. C. \& BartnickiGarcIA, S. (1973). Electron microscopy of zoospores and cysts of Phytophthora palmivora: morphology and surface texture. Archiv für Mikrobiologie 88, 6I-70.

Grove, S. N. (I97I). Protoplasmic correlates of hyphal tip initiation and development in fungi. Ph.D. dissertation, Purdue University, U.S.A.

Hemmes, D. E. \& HoHL, H. R. (I97I). Ultrastructural aspects of encystation and cyst-germination in Phytophthora parasitica. Journal of Cell Science 9, I75-19I.

MoOR, H. \& Muhlethaler, K. (1963). Fine structure in frozen-etched yeast cells. Journal of Cell Biology 17, 609-628.

Pinto da Silva, P. \& Branton, D. (I970). Membrane splitting in freeze-etching. Covalently bound ferritin as a membrane marker. Journal of Cell Biology 45, 598-605.
Pinto Da Silva, P. \& Nogueira, M. L. (I977). Membrane fusion during secretion. A hypothesis based on electron microscope observation of Phytophthora palmivora zoospores during encystment. Journal of Cell Biology 73, 16I-186.

Pinto da Silva, P., Moss, P. S. \& Fudenberg, H. H. (1973). Anionic sites on the membrane intercalated particles of human erythrocyte ghost membranes. Freeze-etch localization. Experimental Cell Research 81, 127-138.

REICHLE, R. E. (1969). Fine structure of Phytophthora parasitica zoospores. Mycologia 6r, 30-5I.

Robinson, D. G. \& Preston, R. D. (1972). Plasmalemma structure in relation to microfibril biosynthesis in Oocystis. Planta ro4, 234-246.

Sing, V.O. \& BARTNICKI-GARCIA, S. (1975). Adhesion of Phytophthora palmivora zoospores: electron microscopy of cell attachment and cyst wall fibril formation. Journal of Cell Science 18, I 23-132.

Streiblová, E. (1968). Surface structure of yeast protoplasts. Journal of Bacteriology 95, 700-707.

TOKunAGA, J. \& BARTNICKI-GARCIA, S. (I97I $a$ ). Cyst wall formation and endogenous carbohydrate utilization during synchronous encystment of Phytophthora palmivora zoospores. Archiv für Mikrobiologie 79, 283-292.

TOKUnAGA, J. \& BARTNICKI-GARCIA, S. (I97I $b$ ). Structure and differentiation of the cell wall of Phytophthora palmivora: cysts, hyphae and sporangia. Archiv für Mikrobiologie 79, 293-310.

VICKERMAN, K. (I969). On the surface coat and flagellar adhesion in trypanosomes. Journal of Cell Science 5, 163-193.

Willison, J. H. M. \& Cocking, E. C. (I975). Microfibril synthesis at the surfaces of isolated tobacco mesophyll protoplasts, a freeze-etch study. Protoplasma 84, 147-1 59. 